\title{
RELAÇÕES ENTRE VARIÁVEIS CLIMÁTICAS COM PRODUÇÃO E ENRAIZAMENTO DE MINIESTACAS DE EUCALIPTO ${ }^{1}$
}

\author{
Ana Catarina Monteiro Carvalho Mori da Cunha ${ }^{2}$, Haroldo Nogueira de Paiva ${ }^{3}$, Helio Garcia Leite ${ }^{3}$, \\ Nairam Félix de Barros $^{4}$ e Fernando Palha Leite ${ }^{5}$
}

\begin{abstract}
RESUMO - O objetivo deste trabalho foi avaliar o grau de associação linear entre variáveis climáticas com a produção e enraizamento de miniestacas de eucalipto cultivado em dois tipos de minijardim clonal (leito de areia e tubetes com subirrigação). Foram utilizados dados da empresa CENIBRA, referentes ao enraizamento de miniestacas e à produção de miniestacas por minicepa, e dados de monitoramento climático. A produção de miniestacas por minicepa e sua taxa de enraizamento foram correlacionadas com os dados climáticos (luz, temperatura e umidade relativa do ar). Verificou-se que a temperatura influencia, de diferentes maneiras, o enraizamento de miniestacas, sendo seu efeito variável de acordo com o clone e tipo de minijardim clonal. Em relação à produção de miniestacas, o aumento da temperatura favorece a produção de miniestacas, independentemente do tipo de minijardim. De modo geral, a luz e a umidade relativa do ar influenciaram positiva e negativamente o enraizamento e a produção de miniestacas, respectivamente, independente do minijardim analisado. Os resultados indicaram que aumento da intensidade luminosa e diminuição da umidade relativa do ar, nos locais onde os minijardins clonais estavam estabelecidos, favorecem tanto o enraizamento de miniestacas quanto a produção de miniestacas pelas minicepas.
\end{abstract}

Palavras-chave: Eucalyptus, minijardim clonal e propagação vegetativa.

\section{RELATION OF CLIMATE VARIABLES WITH EUCALYPT MINICUTTING PRODUCTION AND ROOTING}

\begin{abstract}
The purpose of this study was to evaluate the degree of linear association among climate variables with the production and rooting of Eucalyptus minicuttings cultivated in two types of mini garden (sand bed and sub-irrigation tubes). CENIBRA data were used for minicutting rooting, number of minicuttings per ministump and climate monitoring data. The number of minicuttings produced per ministump and their rooting rate were correlated with climatic data (light, temperature and air relative humidity). Temperature influences minicuting rooting in different ways, with the effect varying according with the clone and type of clonal mini garden. As for the number of minicuttings, temperature increase favors the production of minicuttings, regardless of the type of mini garden. Light influenced rooting and number of minicuttings positively, while air relative humidity had a negative effect, regardless of the type of mini garden evaluated. The data of this study indicates that increased light intensity and reduced air relative humidity favor minicutting rooting and the number of minicuttings produced by ministumps, as well.
\end{abstract}

Keywords: Eucalyptus, clonal mini garden and vegetative propagation.

\footnotetext{
${ }^{1}$ Recebido em 18.07.2007 e aceito para publicação em 06.03.2009.

${ }^{2}$ Programa de Pós-Graduação em Ciência Florestal da Universidade Federal de Viçosa(UFV). E-mail: <catarina_mori@yahoo.com.br>.

${ }^{3}$ Departamento de Engenharia Florestal da UFV. E-mail: <hnpaiva@ufv.br>.

${ }^{4}$ Departamento de Solos da UFV. E-mail: <nfbarros@ufv.br>.

${ }^{5}$ Celulose Nipo Brasileira S A, Departamento de Pesquisa e Desenvolvimento, Depla D. E-mail: <fernando.leite@ cenibra.com.br>.
} 


\section{INTRODUÇÃO}

O plantio de florestas clonais de eucalipto permite a preservação de genótipos de interesse e pode resultar em melhor qualidade e homogeneidade da madeira produzida. O sistema de clonagem tem sido baseado em enraizamento de miniestacas obtidas a partir de genótipos híbridos superiores e, dessa forma, a propagação vegetativa tem se tornado importante ferramenta para aumentar a competitividade das empresas florestais, pois transforma os ganhos genéticos em benefícios para a indústria (ASSIS et al., 2004).

Devido ao seu valor econômico, o gênero Eucalyptus tem-se configurado em modelo para estudo de inúmeros processos fisiológicos em plantas arbóreas. Podem ser citados a rizogênese adventícia em respostas a diversos fatores ambientais (WILSON, 1998; FETTNETO et al., 2001; CORRÊA e FETT-NETO, 2004; CORRÊA et al., 2005); a reguladores de crescimento (DE KLERK et al., 1999; WENDLING e XAVIER, 2005a; FOGAÇA e FETT-NETO, 2005); à nutrição mineral (BELLAMINE et al., 1998; JOSTEN e KUTSCHERA, 1999; SCHWAMBACH et al., 2005); a características genéticas (WENDLING e XAVIER, 2005a); e à juvenilidade dos propágulos (WENDLING e XAVIER, 2005a; WENDLING e XAVIER, 2005b). Esses estudos são importantes no sentido de estabelecerem protocolos para a propagação clonal, propiciando a seleção de genótipos de interesse.

A importância de se conhecer os efeitos dos fatores que afetam a formação de raízes e suas implicações está relacionada ao sucesso ou fracasso da produção de mudas via enraizamento adventício. O enraizamento de espécies lenhosas, mesmo em condições in vitro, é genótipo-dependente. Diferentes espécies, híbridos e, mesmo, distintos clones do mesmo estoque parental podem requerer diferentes condições de cultivo (MOKOTEDI et al., 2000).

O conhecimento das condições de luminosidade, temperatura e umidade relativa do ar ideais para o crescimento e desenvolvimento de vegetais é de suma importância para um eficiente protocolo de propagação, seja in vitro, seja diretamente no substrato, como terra ou vermiculita. No entanto, ainda não há estudos detalhados sobre a influência das condições ambientais sobre a rizogênese do eucalipto.

A intensidade de luz pode influenciar fortemente a produção de brotos e o enraizamento de estacas por redução ou aumento de substâncias fenólicas endógenas, as quais podem agir como inibidores ou promotores, dependendo das concentrações nos tecidos e da espécie (ASSIS et al., 2004). Segundo esses mesmos autores, a luz também pode afetar a concentração endógena de citocininas, que possuem funções inibidoras do enraizamento.

Boas condições de iluminação favorecem o transporte basípeto de auxinas endógenas, se comparadas às plantas sombreadas (MORELLI e RUBERTI, 2002), e consequentemente podem afetar a rizogênese adventícia.

Segundo Hartmann et al. (1997), o equilíbrio entre os níveis de auxina e citocinina é uma das relações primárias na propagação de plantas, em que alta relação auxina/citocinina favorece o enraizamento, ao passo que elevada relação citocinina/auxina favorece a formação de brotações.

A temperatura pode influenciar o enraizamento, atuando, sobretudo na absorção de nutrientes e no metabolismo, especialmente em regiões de clima subtropical. Logo, esse fator ambiental deve ser ajustado para uma ótima produção de miniestacas (CORRÊA e FETT-NETO, 2004). Segundo Hartmann et al. (1997), a divisão celular é favorecida com o aumento da temperatura e, consequentemente, auxilia a formação de raízes e a produção de brotos. No entanto, temperaturas excessivamente altas durante a fase de enraizamento devem ser evitadas por estimularem o desenvolvimento de gemas laterais antes do aparecimento de raízes. Ocorrem também aumento da transpiração e perda de água pelas folhas, provocando a necrose dos tecidos. Já temperaturas baixas diminuem o metabolismo das estacas, levando à menor produção de brotações e ao maior tempo para o enraizamento ou, até mesmo, não proporcionam condições adequadas para que ocorram indução, desenvolvimento e crescimento radicular (XAVIER, 2002).

Para Wilson (1998), a temperatura mais adequada para o enraizamento de explantes está entre 20 e $30^{\circ} \mathrm{C}$. Hansen (1989) observou que a temperatura de $17^{\circ} \mathrm{C}$ por nove semanas seguidas inibiu quase que completamente a emissão de raízes em Stephanotis floribunda, no entanto, com a temperatura inicial de $17^{\circ} \mathrm{C}$ por duas, três ou quatro semanas e depois mantida a $23^{\circ} \mathrm{C}$, a porcentagem de enraizamento de estacas de ramos foi de 92 a $98 \%$.

A umidade constitui um dos fatores primordiais para a propagação vegetativa, sendo mais crítica para as estacas

R. Árvore, Viçosa-MG, v.33, n.2, p.195-203, 2009 
com folhas (ZUFFELATO-RIBAS e RODRIGUES, 2001). A presença de folhas nas estacas é um forte estímulo ao enraizamento, por permitirem que ocorra a fotossíntese, sendo seus produtos (particularmente carboidratos e auxinas) fundamentais para a iniciação radicular. Entretanto, deve-se manter a umidade do ar elevada no ambiente de enraizamento, favorecendo as estacas e reduzindo a transpiração pelas folhas. Quando ocorre murchamento pronunciado das estacas, devido à redução de umidade, danos irreversíveis podem ocorrer; mesmo sob condições normais de umidade, as estacas não voltam a enraizar (HARTMANN et al., 1997).

Diante do exposto, o objetivo deste trabalho foi avaliar as relações entre variáveis climáticas com produção e enraizamento de miniestacas de eucalipto, nos minijardins clonais em leito de areia (fertirrigação por gotejamento) e em tubetes com subirrigação.

\section{MATERIAL E MÉTODOS}

Neste trabalho foram utilizadas informações referentes à produção e enraizamento de miniestacas e aos dados de variáveis climáticas (luz; temperaturas máxima, média e mínima; e umidade relativa do ar) do banco de dados do viveiro da Celulose Nipo-Brasileira S. A. - CENIBRA, localizada no Município de Belo Oriente, $\mathrm{MG}$.

O município de Belo Oriente - MG, localiza-se na região do Vale do Rio Doce, com clima do tipo Aw, segundo a classificação de Köeppen (temperado chuvoso-mesotérmico), latitude de $19^{\circ} 18^{\prime} 23^{\prime \prime}$ S e longitude $42^{\circ} 22^{\prime} 46^{\prime \prime} \mathrm{W}$ e $220 \mathrm{~m}$ de altitude. Apresenta precipitação média anual de $1.163 \mathrm{~mm}$. Temperatura média anual de $25,2^{\circ} \mathrm{C}$, com máxima média de $31,5^{\circ} \mathrm{C}$, mínima média de $19,1^{\circ} \mathrm{C}$, e umidade relativa média de $65,2 \%$ (CARNEIRO et al., 2008).

Os dados analisados foram referentes ao período de janeiro de 2003 a outubro 2005, sendo usados valores de médias mensais, e incluíram os clones que continham maior quantidade de dados disponíveis. Os clones analisados foram: 57, 2719 (clones Eucalyptus grandis x desconhecido); 129, 7074 (clones de Eucalyptus grandis); 386, 908, 911, 957 (clones de Eucalyptus urophylla) e 1046, 1128, 1206, 1207, 1213, 1274 (clones de Eucalyptus grandis x Eucalyptus urophylla). Esses clones constituíam minijardim oriundos do enraizamento de miniestacas propagadas pelo método da estaquia convencional (XAVIER e WENDLING, 1998).

Os dados foram originados de minijardins cultivados em leito de areia sob teto de polietileno translúcido retrátil (móvel), visando minimizar o efeito de temperaturas mais elevadas, com fertirrigação por gotejamento, e outro em que as minicepas eram cultivadas em tubetes com subirrigação, sob abrigo de teto de polietileno translúcido fixo. A fertirrigação foi efetuada através de sistema automatizado, sendo usadas as soluções nutritivas apresentadas nas Tabelas 1 e 2 , das quais foram aplicadas em torno de $5 \mathrm{~L} \mathrm{~m}^{-2}$.

Tabela 1 - Solução nutritiva estoque usada no minijardim clonal cultivado em leito de areia, com fertirrigação por gotejamento

Table 1 - Nutritive stock solution used in the clonal mini garden cultivated in sand bed, with fertirrigation for dripping

\begin{tabular}{lc}
\hline Fertilizante & Concentração $\left(\mathrm{g} 1.000 \mathrm{~L}^{-1}\right)$ \\
\hline Nitrato de cálcio & 33.300 \\
Sulfato de amônio & 13.300 \\
Ácido fosfórico & 3.300 \\
Cloreto de potássio & 11.100 \\
Sulfato de magnésio & 14.400 \\
Ácido bórico & $1.222,2$ \\
Sulfato de zinco & 122,2 \\
Sulfato de cobre & 166,7 \\
Sulfato ferroso & $3.222,2$ \\
EDTA dissódico & $4.666,7$ \\
Sulfato de manganês & 666,7 \\
Molibdato de sódio & 33,3 \\
\hline
\end{tabular}

Tabela 2 - Solução nutritiva estoque usada no minijardim clonal cultivado em tubete, com subirrigação

Table 2 - Nutritive stock solution used in the clonal mini garden cultivated in sub-irrigation tubes

\begin{tabular}{lc}
\hline Fertilizante & Concentração $\left(\mathrm{g} 1.000 \mathrm{~L}^{-1}\right)$ \\
\hline Nitrato de cálcio & 80.000 \\
Sulfato de amônio & 27.800 \\
Ácido fosfórico & 5.000 \\
Cloreto de potássio & 20.000 \\
Sulfato de magnésio & 14.400 \\
Ácido bórico & 311,1 \\
Sulfato de zinco & 27,8 \\
Sulfato de cobre & 42,2 \\
Sulfato ferroso & $1.222,2$ \\
EDTA dissódico & $1.833,3$ \\
Sulfato de manganês & 666,7 \\
Molibdato de sódio & 11,1 \\
\hline
\end{tabular}

R. Árvore, Viçosa-MG, v.33, n.2, p.195-203, 2009 
Para evitar salinização, em ambos os sistemas de cultivo foi aplicada, quinzenalmente, uma lâmina de água pura de $10 \mathrm{~mm}$ e, a cada dois meses, uma lâmina de água pura de $20 \mathrm{~mm}$. A solução nutritiva estoque apresentava condutividade elétrica de 1,0 a $1,5 \mathrm{mS} . \mathrm{cm}^{-1}$, durante os meses mais quentes do ano, e de a 1,5 a 2,0 mS.cm ${ }^{-1}$ nos meses mais frios. Para todos os nutrientes, permitiu-se uma variação de concentração em torno de $10 \%$. O $\mathrm{pH}$ das soluções foi mantido entre 5,5 e 6,5.

A coleta das brotações para preparo de miniestacas foi feita de forma seletiva e contínua, ou seja, sempre que os brotos alcançavam tamanho suficiente para a produção de pelo menos uma miniestaca, de modo a manter as minicepas em bom estado vegetativo e com sistema radicular ativo. A periodicidade das coletas foi de aproximadamente uma coleta por semana. Foram coletadas miniestacas apicais com dimensões variando entre $4 \mathrm{e}$ $6 \mathrm{~cm}$, contendo dois a três pares de folhas, sendo estas cortadas pela metade. A produção média de estacas obtidas a cada mês foi utilizada nas análises estatísticas.

Após serem coletadas e preparadas, as miniestacas foram colocadas em tubetes plásticos (dispostos em bandejas planas) de $50 \mathrm{~cm}^{3}$ contendo um substrato composto de partes iguais de casca de arroz carbonizada e vermiculita de granulometria grossa. Este substrato recebeu adição de $8,0 \mathrm{~kg} \mathrm{~m}^{-3}$ de superfosfato simples; $0,695 \mathrm{~kg} \mathrm{~m}^{-3}$ de sulfato de amônio; $0,208 \mathrm{~kg} \mathrm{~m}^{-3}$ de cloreto de potássio; $0,014 \mathrm{~kg} \mathrm{~m}^{-3}$ de sulfato de zinco; 0,014 $\mathrm{kg} \mathrm{m}^{-3}$ de sulfato de cobre; $0,014 \mathrm{~kg} \mathrm{~m}^{-3} \mathrm{de}$ sulfato de manganês; e $0,028 \mathrm{~kg} \mathrm{~m}^{-3}$ de ácido bórico.

Para o enraizamento, as miniestacas permaneceram em casa de vegetação revestida com polietileno translúcido fixo, em bandejas suspensas. A umidade relativa do ar foi mantida $\geq 80 \%$, por um período de 15 a 25 dias, seguindo, posteriormente, para a casa de sombra, coberta com sombrite com $50 \%$ de interceptação luminosa, por cinco a sete dias. Na saída da casa de sombra, foi feita uma primeira seleção das mudas, separando-se as enraizadas das não enraizadas e agrupando-as por tamanho. As mudas, de acordo com o tamanho, foram transferidas para bandejas, de modo a preencher $30 \%$ de seus orifícios, e permaneceram em uma área de crescimento de 15 a 20 dias. Ao serem retiradas da área de crescimento, foi feita uma segunda seleção das mudas, de modo semelhante à primeira, exceto pela eliminação de brotações laterais, deixandose apenas mudas com uma haste. As mudas permaneceram na área de aclimatação a pleno sol por aproximadamente 20 dias até serem expedidas. Os dados utilizados corresponderam à média mensal de enraizamento.

Os dados referentes à radiação, à umidade relativa do ar e à temperatura foram obtidos de uma estação climatológica automática, instalada próxima ao viveiro da empresa. O sensor de temperatura e umidade relativa do ar usado foi um Vaisala modelo HMP45C e o sensor de radiação fotossinteticamente ativa (luz), um Kipp e Zonen modelo PAR LITE - LI190SB. Os dados climáticos foram coletados diariamente, mas nas análises foram usadas médias mensais.

Para a análise dos dados, foi utilizado um critério temporal, de modo que os dados coletados foram pareados mensalmente para poder estabelecer o grau de associação linear entre as variáveis climáticas e a produção e o enraizamento das miniestacas. As análises foram feitas utilizando-se o software Statistica, versão 7.0, para cada tipo de cultivo. As hipóteses avaliadas foram:

$$
\begin{aligned}
& H_{O(i j)}: \rho_{X i Y j}=0 \\
& H_{a(i j)}: \text { não } H_{O(i j)} \\
& \rho_{X i Y j}: \text { coeficiente de correlação linear entre as variáveis }
\end{aligned}
$$
aleatórias $\mathrm{X}_{\mathrm{i}}$ e $\mathrm{Y}_{\mathrm{j}}$;

j: 1 e 2 (\% de enraizamento e produtividade de miniestacas por minicepa); e

\section{i: 1, 2, 3, 4, 5 (variáveis climáticas).}

Essas hipóteses foram avaliadas pela estatística F para níveis de significância de 5\%,10\% e $15 \%$ de probabilidade.

\section{RESULTADOS E DISCUSSÃO}

As correlações entre as variáveis climáticas e as taxas de enraizamento das miniestacas dos clones de Eucalyptus, no minijardim clonal em leito de areia e no minijardim clonal em tubetes, estão nas Tabelas 3 e 4 , respectivamente.

No minijardim clonal em leito de areia, não foi observada correlação significativa entre a radiação e a taxa de enraizamento das miniestacas. A radiação exerceu efeito positivo no enraizamento, no minijardim clonal em tubetes em 5 dos 14 clones avaliados, de modo que aumento nos índices de radiação fotossinteticamente ativa possivelmente aumentaria as taxas de enraizamento dos respectivos clones. FettNeto et al. (2001) também observaram influência da luz sobre a rizogênese adventícia. 
Tabela 3 - Coeficiente de correlação de Pearson entre os dados climáticos e as taxas de enraizamento das miniestacas dos clones de Eucalyptus, no minijardim clonal em leito de areia

Table 3 - Pearson's correlation coefficient between climatic data and minicutting rooting rates of clonal Eucalyptus, in mini garden on sand bed

\begin{tabular}{|c|c|c|c|c|c|c|c|}
\hline \multirow[t]{2}{*}{ Clones } & \multirow{2}{*}{$\begin{array}{c}\text { Médias de } \\
\text { Enraizamento }(\%)\end{array}$} & \multirow{2}{*}{$\begin{array}{l}\text { Número de } \\
\text { Observações }\end{array}$} & \multicolumn{5}{|c|}{ Monitoramento Climático } \\
\hline & & & Luz & $\begin{array}{l}\text { Temp } \\
\text { min }\end{array}$ & $\begin{array}{c}\text { Temp } \\
\text { med }\end{array}$ & $\begin{array}{c}\text { Temp } \\
\max \end{array}$ & Umidade \\
\hline 57 & 87,3 & 35 & $0,00^{\mathrm{ns}}$ & $-0,60^{1}$ & $-0,52^{1}$ & $-0,36^{1}$ & $-0,41^{1}$ \\
\hline 129 & 87,1 & 33 & $0,13^{\text {ns }}$ & $-0,26^{3}$ & $-0,09 \mathrm{~ns}$ & $0,14^{\text {ns }}$ & $-0,62^{1}$ \\
\hline 386 & 84,6 & 34 & $0,00^{\mathrm{ns}}$ & $-0,26^{3}$ & $-0,12^{\mathrm{ns}}$ & $0,06^{\mathrm{ns}}$ & $-0,37^{1}$ \\
\hline 908 & 75,6 & 21 & $-0,20^{\mathrm{ns}}$ & $-0,59^{1}$ & $-0,54^{1}$ & $-0,38^{2}$ & $-0,15^{\mathrm{ns}}$ \\
\hline 911 & 85,5 & 35 & $0,00^{\mathrm{ns}}$ & $-0,34^{1}$ & $-0,25^{3}$ & $-0,11^{\mathrm{ns}}$ & $-0,22^{\mathrm{ns}}$ \\
\hline 957 & 83,2 & 33 & $-0,23^{\mathrm{ns}}$ & $-0,21^{\mathrm{ns}}$ & $-0,19 \mathrm{~ns}$ & $-0,16^{\mathrm{ns}}$ & $-0,12^{\mathrm{ns}}$ \\
\hline 1046 & 73,9 & 34 & $-0,06^{\mathrm{ns}}$ & $-0,03^{\mathrm{ns}}$ & $0,03^{\mathrm{ns}}$ & $0,12^{\mathrm{ns}}$ & $-0,15^{\mathrm{ns}}$ \\
\hline 1128 & 79,5 & 35 & $-0,13^{\mathrm{ns}}$ & $-0,48^{1}$ & $-0,39^{1}$ & $-0,28^{3}$ & $-0,34^{1}$ \\
\hline 1206 & 78,0 & 35 & $0,08^{\mathrm{ns}}$ & $-0,15^{\mathrm{ns}}$ & $-0,14^{\mathrm{ns}}$ & $-0,15^{\mathrm{ns}}$ & $-0,11^{\mathrm{ns}}$ \\
\hline 1207 & 73,1 & 35 & $0,00^{\mathrm{ns}}$ & $-0,06^{\mathrm{ns}}$ & $-0,08^{\mathrm{ns}}$ & $-0,12^{\mathrm{ns}}$ & $-0,08^{\mathrm{ns}}$ \\
\hline 1213 & 79,5 & 35 & 0,22 ns & $-0,02^{\mathrm{ns}}$ & $0,13^{\mathrm{ns}}$ & $0,32^{2}$ & $-0,32^{2}$ \\
\hline 1274 & 81,4 & 35 & $0,10^{\mathrm{ns}}$ & $-0,16^{\mathrm{ns}}$ & $-0,07^{\mathrm{ns}}$ & $0,03^{\mathrm{ns}}$ & $-0,26^{3}$ \\
\hline 2719 & 88,5 & 32 & $-0,08^{\mathrm{ns}}$ & $-0,32^{2}$ & $-0,24 \mathrm{~ns}$ & $-0,10^{\mathrm{ns}}$ & $-0,38^{1}$ \\
\hline 7074 & 82,5 & 34 & $0,07^{\text {ns }}$ & $-0,40^{1}$ & $-0,29^{2}$ & $-0,12^{\mathrm{ns}}$ & $-0,30^{2}$ \\
\hline
\end{tabular}

${ }^{1}=$ significativo a $5 \%$ de probabilidade de erro ${ }^{2}=$ significativo a $10 \%$ de probabilidade de erro; ${ }^{3}=$ significativo a $15 \%$ de probabilidade de erro; e ns = não-significativo.

Tabela 4 - Coeficiente de correlação de Pearson entre os dados climáticos e as taxas de enraizamento das miniestacas dos clones de Eucalyptus, no minijardim clonal em tubetes

Table 4-Pearson's correlation coefficient between the climatic data and minicutting rooting rates of clonal Eucalyptus, in the clonal mini garden with sub-irrigation tubes

\begin{tabular}{|c|c|c|c|c|c|c|c|}
\hline \multirow[t]{2}{*}{ Clones } & \multirow{2}{*}{$\begin{array}{c}\text { Médias de } \\
\text { Enraizamento }(\%)\end{array}$} & \multirow{2}{*}{$\begin{array}{l}\text { Número de } \\
\text { Observações }\end{array}$} & \multicolumn{5}{|c|}{ Monitoramento Climático } \\
\hline & & & Luz & $\begin{array}{l}\text { Temp } \\
\min \end{array}$ & $\begin{array}{c}\text { Temp } \\
\text { med }\end{array}$ & $\begin{array}{c}\text { Temp } \\
\max \end{array}$ & Umidade \\
\hline 57 & 81,3 & 31 & $-0,14^{\mathrm{ns}}$ & $-0,60^{1}$ & $-0,47^{1}$ & $-0,26^{3}$ & $-0,47^{1}$ \\
\hline 129 & 84,2 & 2 & $0,57^{1}$ & $-0,01^{\mathrm{ns}}$ & $0,20^{\mathrm{ns}}$ & $0,47^{1}$ & $-0,50^{1}$ \\
\hline 386 & 81,3 & 34 & $0,15^{\mathrm{ns}}$ & $-0,02^{\mathrm{ns}}$ & $0,12^{\mathrm{ns}}$ & $0,32^{2}$ & $-0,26^{3}$ \\
\hline 908 & 74,2 & 20 & $-0,09^{\mathrm{ns}}$ & $-0,44^{2}$ & $-0,30^{\mathrm{ns}}$ & $-0,11^{\mathrm{ns}}$ & $-0,39^{2}$ \\
\hline 911 & 84,7 & 23 & $0,52^{1}$ & $0,36^{2}$ & $0,49^{1}$ & $-0,34^{3}$ & $0,55^{1}$ \\
\hline 957 & 76,8 & 19 & 0,32 ns & $0,31^{\text {ns }}$ & $0,46^{1}$ & $0,67^{1}$ & $-0,14^{\mathrm{ns}}$ \\
\hline 1046 & 72,4 & 32 & $0,47^{1}$ & $0,34^{2}$ & $0,54^{1}$ & $0,68^{1}$ & $-0,55^{1}$ \\
\hline 1128 & 74,6 & 30 & $0,11^{\mathrm{ns}}$ & $-0,17^{\mathrm{ns}}$ & $-0,17^{\mathrm{ns}}$ & $-0,15^{\mathrm{ns}}$ & $0,02^{\mathrm{ns}}$ \\
\hline 1206 & 67,9 & 15 & $0,21^{\mathrm{ns}}$ & $-0,04^{\mathrm{ns}}$ & $0,03^{\mathrm{ns}}$ & $0,03^{\mathrm{ns}}$ & $-0,35^{\mathrm{ns}}$ \\
\hline 1207 & 67,2 & 22 & $-0,18^{\mathrm{ns}}$ & $0,11^{\mathrm{ns}}$ & $0,05^{\text {ns }}$ & $-0,07 \mathrm{~ns}$ & $0,04^{\text {ns }}$ \\
\hline 1213 & 76,8 & 35 & $0,33^{2}$ & $0,41^{1}$ & $0,47^{1}$ & $0,52^{1}$ & $-0,09^{\mathrm{ns}}$ \\
\hline 1274 & 76,6 & 30 & $0,23^{\mathrm{ns}}$ & 0,19 ns & $0,28^{3}$ & $0,34^{2}$ & $-0,19^{\mathrm{ns}}$ \\
\hline 2719 & 86,9 & 33 & $0,18^{\text {ns }}$ & $0,044^{\text {ns }}$ & $0,21^{\text {ns }}$ & $0,39^{1}$ & $-0,48^{1}$ \\
\hline 7074 & 79,0 & 35 & $0,42^{1}$ & 0,25 ns & $0,43^{1}$ & $0,58^{1}$ & $-0,56^{1}$ \\
\hline
\end{tabular}

${ }^{1}=$ significativo a $5 \%$ de probabilidade de erro $;{ }^{2}=$ significativo a $10 \%$ de probabilidade de erro ${ }^{3}=$ significativo a $15 \%$ de probabilidade de erro; e ns = não-significativo.

Os resultados encontrados não estão de acordo com o relatado por Borges (1978) e Bassuk e Maynard (1987), os quais mencionaram que redução da luz natural nos jardins clonais possui efeito altamente significativo sobre a formação de raízes. No entanto,
Poggiani et al. (1990) relataram que cada espécie tem exigências próprias para o seu desenvolvimento, sendo a intensidade de luz que chega ao indivíduo especialmente importante para seu crescimento e desenvolvimento. 
Alfenas et al. (2004) afirmaram que a luz influencia indiretamente o enraizamento, pois os produtos da fotossíntese, particularmente carboidratos e reguladores de crescimento, são fundamentais para a iniciação e desenvolvimento radicular. Esses mesmos autores salientaram ainda que se deve fornecer luminosidade satisfatória, sendo essa variável entre espécies, variedades e clones, de modo a obter níveis adequados de fotossíntese e, consequentemente, acúmulo de reservas e substâncias indutoras de enraizamento.

Boas condições de iluminação favorecem o transporte basípeto de auxinas endógenas, se comparado com as plantas sombreadas (MORELLI e RUBERTI, 2002), e, consequentemente, podem afetar a rizogênese adventícia, promovendo aumento nos índices de enraizamento.

Corrêa (2005) observou redução na resposta rizogênica de estacas retiradas de plantas de Eucalyptus saligna, após a exposição destas a quatro semanas de escuro, o que foi parcialmente recuperado com o uso de sacarose no meio de cultivo. Poucas diferenças foram notadas em estacas provenientes de plantasmãe sob 30 a $60 \mu \mathrm{mol} \cdot \mathrm{m}^{-2} \cdot \mathrm{s}^{-1}$ de radiação fotossinteticamente ativa.

No minijardim clonal em leito de areia, foram observadas correlações negativas em relação à temperatura, de modo geral, à exceção do clone 1213 . Dessa forma, é necessária uma mudança no manejo desse minijardim, de modo a diminuir a temperatura e, consequentemente, aumentar o enraizamento.

Já no minijardim clonal em tubetes foram observadas correlações positivas, exceto nos clones 57 (em todos os níveis de temperatura) e 908 (temperatura mínima), no entanto, somente 22 possibilidades, num total de 42 , foram significativas.

A temperatura tem importante função regulatória no metabolismo das plantas, afetando o enraizamento; ainda, a divisão celular é favorecida com o aumento da temperatura e, consequentemente, auxilia a formação de raízes. No entanto, temperatura excessivamente alta, durante a fase de enraizamento, estimula o desenvolvimento de gemas laterais antes do aparecimento de raízes (HARTMANN et al., 1997).

No período de coleta dos dados foi verificada ampla variação de temperatura (Figura 1), sendo esta maior nos meses mais frios. Segundo Gomes (1987), amplas oscilações térmicas são altamente deletérias ao enraizamento. Essa variação na temperatura pode explicar a maioria dos efeitos negativos verificados no minijardim clonal em leito de areia. Por existir nesse minijardim o sistema de teto retrátil, as variações de temperatura podem estar atuando de forma mais intensa que no minijardim clonal em tubetes (com teto fixo), o que explicaria as diferenças encontradas nos dois tipos de minijardim, tendo em vista a afirmação de Corrêa e Fett-Neto (2004) de que a temperatura pode influenciar o enraizamento, atuando principalmente na absorção de nutrientes e no metabolismo.

A umidade relativa do ar, no ambiente onde as miniestacas foram produzidas, influenciou negativamente o enraizamento, independentemente do tipo de minijardim. Segundo Xavier (2002), o excesso de umidade é prejudicial, por dificultar as trocas gasosas e propiciar o desenvolvimento de doenças. Ainda, a umidade relativa do ar influencia indiretamente o posterior enraizamento das miniestacas produzidas nos minijardins clonais, pois afeta a taxa fotossintética e, consequentemente, seus produtos, que são importantes no processo de enraizamento, da mesma forma como anteriormente mencionado no caso de radiação. Dessa forma, podese inferir que esteja ocorrendo excesso de umidade relativa do ar, o que poderia estar prejudicando a posterior formação de raízes.

As correlações entre as variáveis climáticas e a produção de miniestacas por minicepa dos clones de Eucalyptus, no minijardim clonal em leito de areia e no minijardim clonal em tubetes, estão nas Tabelas 5 e 6 , respectivamente.

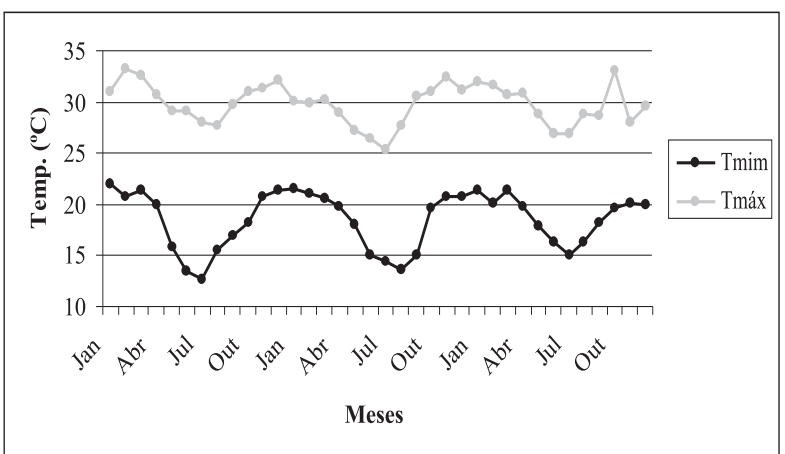

Figura 1 - Temperaturas mínimas e máximas observadas no período de coleta dos dados (jan./2003 a out./ 2005).

Figure 1-Minimum and maximum temperatures observed during data collection (Jan, 2003 to Oct, 2005). 
Tabela 5 - Coeficiente de correlação de Pearson entre os dados climáticos e a produtividade das minicepas dos clones de Eucalyptus, no minijardim clonal em leito de areia

Table 5 - Pearson's correlation coefficient between the climatic data and productivity of the clonal Eucalyptus ministumps at the clonal mini garden on the sand bed

\begin{tabular}{|c|c|c|c|c|c|c|c|}
\hline \multirow[t]{2}{*}{ Clones } & \multirow{2}{*}{$\begin{array}{c}\text { Média Mensal } \\
\text { do } \mathrm{n}^{\circ} \text { de } \\
\text { Miniestacas }\end{array}$} & \multirow{2}{*}{$\begin{array}{l}\text { Número de } \\
\text { Observações }\end{array}$} & \multicolumn{5}{|c|}{ Monitoramento Climático } \\
\hline & & & Luz & $\begin{array}{c}\text { Temp } \\
\text { min }\end{array}$ & $\begin{array}{c}\text { Temp } \\
\text { med }\end{array}$ & $\begin{array}{c}\text { Temp } \\
\max \end{array}$ & Umidade \\
\hline 57 & 9,4 & 30 & $0,17^{\mathrm{ns}}$ & $0,00^{\mathrm{ns}}$ & $0,17^{\mathrm{ns}}$ & $0,25^{\mathrm{ns}}$ & $-0,44^{1}$ \\
\hline 129 & 9,5 & 28 & $0,41^{1}$ & $0,37^{2}$ & $0,49^{1}$ & $0,48^{1}$ & $-0,42^{1}$ \\
\hline 386 & 8,9 & 30 & $0,35^{2}$ & $0,40^{1}$ & $0,51^{1}$ & $0,54^{1}$ & $-0,17^{\mathrm{ns}}$ \\
\hline 908 & 8,5 & 16 & $-0,33^{\mathrm{ns}}$ & $0,09^{\mathrm{ns}}$ & $0,14^{\mathrm{ns}}$ & $0,17^{\mathrm{ns}}$ & $-0,18^{\mathrm{ns}}$ \\
\hline 911 & 7,8 & 30 & $0,20^{\mathrm{ns}}$ & $0,34^{2}$ & $0,34^{2}$ & $0,25^{\mathrm{ns}}$ & $-0,01^{\mathrm{ns}}$ \\
\hline 957 & 9,9 & 28 & $0,47^{1}$ & $0,18^{\mathrm{ns}}$ & $0,28^{3}$ & $0,35^{2}$ & $-0,29^{3}$ \\
\hline 1046 & 10,0 & 29 & $-0,26^{\mathrm{ns}}$ & $0,04^{\mathrm{ns}}$ & $0,05^{\mathrm{ns}}$ & $0,08^{\mathrm{ns}}$ & $0,05^{\mathrm{ns}}$ \\
\hline 1128 & 7,7 & 28 & $0,23^{\mathrm{ns}}$ & $0,49^{1}$ & $0,56^{1}$ & $0,52^{1}$ & $-0,10^{\mathrm{ns}}$ \\
\hline 1206 & 7,6 & 29 & $0,17^{\mathrm{ns}}$ & $0,12^{\mathrm{ns}}$ & $0,12^{\mathrm{ns}}$ & $0,08^{\mathrm{ns}}$ & $-0,10^{\mathrm{ns}}$ \\
\hline 1207 & 7,6 & 29 & $0,29^{3}$ & $0,28^{3}$ & $0,32^{2}$ & $0,28^{3}$ & $-0,16^{\mathrm{ns}}$ \\
\hline 1213 & 11,8 & 30 & $0,20^{\mathrm{ns}}$ & $0,35^{2}$ & $0,49^{1}$ & $0,56^{1}$ & $-0,25^{\mathrm{ns}}$ \\
\hline 1274 & 10,9 & 30 & $0,24^{\mathrm{ns}}$ & $0,30^{3}$ & $0,38^{1}$ & $0,48^{1}$ & $-0,01^{n s}$ \\
\hline 2719 & 8,9 & 28 & $-0,09 \mathrm{~ns}$ & $-0,25^{\mathrm{ns}}$ & $-0,18^{\mathrm{ns}}$ & $-0,07 \mathrm{~ns}$ & $-0,01^{\mathrm{ns}}$ \\
\hline 7074 & 10,2 & 30 & $0,27^{3}$ & $0,20^{\mathrm{ns}}$ & $0,33^{2}$ & $0,39^{1}$ & $-0,38^{1}$ \\
\hline
\end{tabular}

${ }^{1}=$ significativo a $5 \%$ de probabilidade de erro ${ }^{2}=$ significativo a $10 \%$ de probabilidade de erro; ${ }^{3}=$ significativo a $15 \%$ de probabilidade de erro; e ns = não-significativo.

Tabela 6 - Coeficiente de correlação de Pearson entre os dados climáticos e a produtividade das minicepas dos clones de Eucalyptus, no minijardim clonal em tubetes

Table 6 - Pearson's correlation coefficient between the climatic data and productivity of the clonal Eucalyptus ministumps in the clonal mini garden on the sub-irrigation tubes

\begin{tabular}{|c|c|c|c|c|c|c|c|}
\hline \multirow[t]{2}{*}{ Clones } & \multirow{2}{*}{$\begin{array}{l}\text { Média Mensal } \\
\text { do } \mathrm{n}^{\circ} \text { de } \\
\text { Miniestacas }\end{array}$} & \multirow{2}{*}{$\begin{array}{l}\text { Número de } \\
\text { Observações }\end{array}$} & \multicolumn{5}{|c|}{ Monitoramento Climático } \\
\hline & & & Luz & $\begin{array}{c}\text { Temp } \\
\text { min }\end{array}$ & $\begin{array}{c}\text { Temp } \\
\text { med }\end{array}$ & $\begin{array}{l}\text { Temp } \\
\max \end{array}$ & Umidade \\
\hline 57 & 2,4 & 26 & $0,34^{2}$ & $-0,07^{\mathrm{ns}}$ & $0,07^{\text {ns }}$ & $0,17^{\text {ns }}$ & $-0,39^{1}$ \\
\hline 129 & 3,0 & 18 & $0,19^{\mathrm{ns}}$ & $0,15^{\text {ns }}$ & $0,29^{\mathrm{ns}}$ & $0,36^{3}$ & $-0,49^{1}$ \\
\hline 386 & 2,8 & 29 & $0,28^{\mathrm{ns}}$ & $0,20^{\mathrm{ns}}$ & $0,38^{1}$ & $0,54^{1}$ & $-0,51^{1}$ \\
\hline 908 & 2,6 & 13 & $-0,03^{\mathrm{ns}}$ & 0,20 ns & $0,04^{\mathrm{ns}}$ & $-0,14^{\mathrm{ns}}$ & $0,39^{\mathrm{ns}}$ \\
\hline 911 & 2,8 & 14 & $0,73^{1}$ & $0,58^{1}$ & $0,69^{1}$ & $0,69^{1}$ & $-0,36^{\mathrm{ns}}$ \\
\hline 957 & - & - & - & - & - & - & - \\
\hline 1046 & 2,5 & 27 & $0,24^{\mathrm{ns}}$ & 0,00 ns & $0,09^{\mathrm{ns}}$ & $0,20^{\mathrm{ns}}$ & $-0,18^{\mathrm{ns}}$ \\
\hline 1128 & 2,6 & 20 & $0,37^{3}$ & $0,35^{3}$ & $0,32^{\mathrm{ns}}$ & $0,25^{\mathrm{ns}}$ & $0,01^{\mathrm{ns}}$ \\
\hline 1206 & - & - & - & - & - & - & - \\
\hline 1207 & - & - & - & - & - & - & - \\
\hline 1213 & 3,2 & 30 & $0,13^{\mathrm{ns}}$ & 0,24 ns & $0,30^{3}$ & $0,34^{2}$ & $-0,18^{n s}$ \\
\hline 1274 & 3,2 & 22 & $0,07^{\mathrm{ns}}$ & $0,37^{2}$ & $0,35^{3}$ & 0,25 ns & $-0,08^{n s}$ \\
\hline 2719 & 3,2 & 29 & $0,25^{\mathrm{ns}}$ & $0,05^{\mathrm{ns}}$ & $0,16^{\mathrm{ns}}$ & $0,32^{2}$ & $-0,09^{\mathrm{ns}}$ \\
\hline 7074 & 3,1 & 30 & $0,10^{\mathrm{ns}}$ & $0,23^{\mathrm{ns}}$ & $0,36^{1}$ & $0,45^{1}$ & $-0,33^{2}$ \\
\hline
\end{tabular}

${ }^{1}=$ significativo a $5 \%$ de probabilidade de erro $;{ }^{2}=$ significativo a $10 \%$ de probabilidade de erro; ${ }^{3}=$ significativo a $15 \%$ de probabilidade de erro; e ns = não-significativo.

A luz influenciou positivamente a produtividade das minicepas, nos dois sistemas de cultivo, exceto no clone 908 (nos dois minijardins) e nos clones 1046 e 2719 (no minijardim clonal em leito de areia), indicando que suplementação nos índices de radiação fotossinteticamente ativa seria favorável, visando a um aumento da produção de miniestacas.

Segundo Assis et al. (2004), a intensidade de luz pode influenciar fortemente a produção e enraizamento de estacas por redução ou aumento de substâncias 
fenólicas endógenas, as quais podem agir como inibidores ou promotores, dependendo das concentrações nos tecidos e da espécie. Segundo esses mesmo autores, a luz também pode afetar a concentração endógena de citocininas, que possuem funções inibidoras do enraizamento.

Em relação à temperatura, foram observados efeitos positivos em todos os níveis, exceto no clone 2719 (no minijardim clonal em leito de areia), nos dois tipos de minijardim. Os resultados indicam que o aumento da temperatura implicaria aumento na produção de miniestacas.

Segundo Wendling et al. (1999), a produção de miniestacas apresenta variação conforme a temperatura que pode influenciar na emissão de novas brotações, ou seja, temperaturas mais elevadas estão relacionadas à maior produtividade das minicepas devido ao maior crescimento vegetativo encontrado nessas condições, ao contrário do que ocorre sob temperaturas mais baixas.

Rosa (2006) observou menor produção de miniestacas no período de temperaturas mais baixas ao trabalhar com Eucalyptus dunnii no processo de miniestaquia, o que está de acordo com os resultados observados neste trabalho, já que aumento da temperatura mínima favorece a produtividade das minicepas, nos diferentes tipos de minijardim clonal.

Com relação a umidade relativa do ar, foram observadas correlações negativas para a produção de miniestacas, em ambos os minijardins. No período de coleta dos dados, foi verificada uma média de umidade relativa do ar em torno de $80 \%$, o que pode estar influenciando negativamente a produção de brotos, tendo em vista as consequências ocasionadas pela alta umidade relativa do ar, conforme relatado por Xavier (2002), o que poderia estar prejudicando a produção de miniestacas produzidas pelas minicepas.

Observou-se que, de modo geral, embora significativo em alguns casos, os valores de correlação encontrados foram baixos, em sua maioria. No entanto, baixos valores de correlação não implicam ausência de relação entre as variáveis analisadas, posto que somente os baixos valores não são lineares. Dessa forma, os valores de correlação observados não são satisfatórios para explicar, com segurança, o comportamento das variáveis climáticas relacionadas à produção e enraizamento de miniestacas. Assim, os resultados podem estar indicando que as condições do viveiro onde estão instalados os minijardins clonais são boas e, de certa forma, homogêneas, ressaltando-se que as variáveis climáticas, nas condições em que os dados foram coletados, desempenham pouco efeito sobre o enraizamento e a produção de miniestacas.

\section{CONCLUSÕES}

Diante dos resultados, concluiu-se que:

-As variáveis climáticas apresentam pequena influência sobre o enraizamento e produção de miniestacas, nas condições dos minijardins clonais estudados.

- Para a maioria dos clones estudados, aumentos na intensidade luminosa e diminuição da umidade relativa do ar favorecem tanto o enraizamento quanto a produção de miniestacas.

- O fator temperatura influencia, de diferentes maneiras, o enraizamento de miniestacas, sendo dependente dos clones e do tipo de minijardim clonal. Em relação à produção de miniestacas, aumento de temperatura é indicado, independentemente do tipo de minijardim.

\section{AGRADECIMENTOS}

À Capes, pela bolsa de estudo; ao CNPq, pela bolsa de produtividade em pesquisa; e à Celulose NipoBrasileira S.A. - CENIBRA, pela concessão do banco de dados usados no trabalho.

\section{REFERÊNCIAS}

ALFENAS, A. C. et al. Clonagem e doenças do eucalipto. Viçosa, MG: Universidade Federal de Viçosa, 2004. 442p.

ASSIS, T. F.; FETT-NETO, A. G.; ALFENAS, A. C. Current techniques and prospects for the clonal propagation of hardwood with emphasis on Eucalyptus. In: WALTER. C.; CARSON, M. Plantation forest biotechnology for the $2^{\text {th }}$ century. New Delhi: Research Sign Post, 2004. v.1 p.303-333.

BASSUK, N.; MAYNARD, B. Stock plant etiolation. Hortscience, v.22, n.5, p.749-750, 1987.

BELLAMINE, J. et al. Confirmation of the role of auxin and calcium in the late phases of adventitious root formation. Plant Growth Regulation, v.26, n.3, p.191-194, 1998.

BORGES, E. E. L. Enraizamento de estacas de Eucalyptus saligna e Eucalyptus grandis. 1978. 78f. Dissertação (Mestrado em Ciência Florestal) Universidade Federal de Viçosa, Viçosa, MG, 1978. 
CARNEIRO, R. L. de C.; RIBEIRO, A.; HUAMAN, C. A. M. y; LEITE, F. P.; SEDIYAMA, G. C.; BARROS, N. F. de Consumo de água em plantios de eucalipto: parte 1 determinação da condutância estomática em tratamentos irrigado e não-irrigado. Revista Árvore, v.32, n.1, p.1-10, 2008.

CORRÊA, L. R.; FETT-NETO, A. G. Effects of temperature on adventitious root development in microcuttings of Eucaltptus saligna Smith and Eucaltptus globulus Labill. Journal of Thermal Biology, v.29, p.315-324, 2004.

CORRÊA, L. R. et al. Carbohydrates as regulatory factors on the rooting of Eucalyptus saligna Smith and Eucalyptus globulus Labill. Plant Growth Regulation, v.45, v.1, p.63-73, 2005.

DE KLERK, G. J.; van der KRIEKEN, W.; DE JONG, J. G. Review - The formation of adventitious roots: New concepts, new possibilities. In Vitro Cellular \& Developmental Biology Plant, v.35, n.3, p.189-199, 1999.

FETT-NETO, A. G. et al. Distinct effects of auxin and light on adventitious root development in Eucalyptus saligna and Eucalyptus globulus. Tree Physiology, v.21, n.7, p.457-464, 2001.

FOGAÇA, C. M.; FETT-NETO, A. G. Role of auxin and its modulators in the adventitious rooting of Eucalyptus species differing in recalcitrance. Plant Growth Regulation, v.45, n.1, p.1-10, 2005.

GOMES, A. L. Propagação clonal: princípios e particularidades. Vila Real: Universidade de Trás-os-Montes e Alto Douro, 1987. 69p.

HANSEN, J. Influence of cutting position and temperature during rooting on adventitious root formation and axilary bud break of Stephanotis floribunda. Scientia Horticulturae, v.40, n.4, p.345-354, 1989.

HARTMANN, H. T. et al. Plant propagation: principles and practices. 6.ed. New Jersey: Prentice-Hall, 1997. 770p.

JOSTEN, P. \& KUTSCHERA, U. The micronutrient boron causes the development of adventitious roots in sunflower cuttings. Annals of Botany, v.84, n.3, p.337-342, 1999.

MOKOTEDI, M. E. O. et al. In vitro rooting and subsequent survival of two clones of cold-tolerant Eucalyptus grandis X Eucalyptus nitens Hybrid. Hortscience, v.35, n.6, p.1163-1165, 2000.
MORELLI, G.; RUBERTI, I. Light and shade in the photocontrol of Arabidopsis growth. Trends in Plant Science, v.7, n.9, p.399-404, 2002.

POGGIANI, F.; BRUNI, S.; BARBOSA, E. S. Q. Efeito do sombreamento das mudas de três espécies florestais. Revista do Instituto Florestal de São Paulo, v.4, n.2, p.564-569, 1990.

\section{ROSA, L. S. Adubação nitrogenada e} substratos na miniestaquia de Eucalyptus dunnii Maiden. 2006. 89f. Dissertação (Mestrado em Engenharia Florestal) Universidade Federal do Paraná, Curitiba, 2006.

SCHAWAMBACH, J.; FADANELLI, C.; FETTNETO, A. G. Mineral nutrition and adventitious rooting in microcuttings of Eucalyptus globulus. Tree Physiology, v.25, p. 487-494, 2005.

WENDLING, I.; XAVIER, A.; TITON, M. Miniestaquia na silvicultural clonal de Eucalyptus. Folha Florestal, v.1, p.16-17, 1999.

WENDLING, I. \& XAVIER, A. Influência do ácido indolbutírico e da miniestaquia seriada no enraizamento e vigor de miniestacas de clones de Eucalyptus grandis. Revista Árvore, v.29, n.6, p.921-930, 2005a.

WENDLING, I. \& XAVIER, A. Influência da miniestaquia seriada no vigor radicular de clones de Eucalyptus grandis. Revista Árvore, v.29, n.5, p.681-689, 2005b.

WILSON, P. J. Environmental preferences of Eucalyptus globulus stem cuttings in one nursery. New Zealand Journal of Forestry Science, v.28, n.3, p.304-315, 1998.

XAVIER, A.; WENDLING, I. Miniestaquia na clonagem de Eucalyptus. Viçosa, MG: SIF, 1998. 10p.

XAVIER, A. Silvicultura clonal I: princípios e técnicas de propagação vegetativa. Viçosa, MG: Universidade Federal de Viçosa, 2002. 64p. (Caderno Didático, 92).

ZUFFELLATO-RIBAS, K. C.; RODRIGUES, J. D. Estaquia: uma abordagem dos principais aspectos fisiológicos. Curitiba: Universidade Federal do Paraná, 2001. 39p.

R. Árvore, Viçosa-MG, v.33, n.2, p.195-203, 2009 